\title{
Percepções sobre as contribuições do design nos processos de inovação da gestão pública
}

\author{
A discussion on the contributions of design to the innovation \\ processes in public management
}

Dara Costa Rattes, Tiago Barros Pontes e Silva

design, inovação, setor público, governança

O trabalho consiste numa pesquisa exploratória qualitativa sobre as diferentes percepções de contribuições do design nos processos de inovação da gestão pública, tendo como base um levantamento bibliográfico e uma pesquisa empírica com entrevistas com profissionais do setor público ( $n=11)$, traçando um panorama inicial do momento atual. Como resultado, foram propostas discussões relacionadas às metodologias do design e a sua aplicação no contexto da gestão pública no Brasil, evidenciando-se as principais oportunidades de ampliação dessas contribuições.

design, innovation, public sector, governance

The paper describes a qualitative exploratory research on the realizations of contributions of design in the innovation processes of public management, based on a bibliographic survey and an empirical research with open interviews with professionals from the public sector $(n=11)$, tracing an initial panorama of the current moment. As a result, discussions related to design methodologies and their application in the context of public management in Brazil were raised, highlighting the main opportunities for expanding these contributions.

\section{Introdução}

Diante de uma realidade social cada vez mais complexa em um país tão heterogêneo, o setor público, considerado essencial para a manutenção de direitos necessários ao cidadão, se mostra demasiadamente complexo. Esta complexidade se dá por diversas razões, destacandose os chamados "wicked problems", problemas multissetoriais contemporâneos que dificilmente serão totalmente resolvidos, como, por exemplo, as questões ambientais e a desigualdade social - e o contexto múltiplo da gestão pública brasileira, que é a responsável por lidar com estes problemas. Consequentemente, as dificuldades a serem enfrentadas são diversas, em relação ao contexto político e econômico, o contexto interno das organizações, os desafios tecnológicos e informacionais, dentre outros.

Portanto, o conceito de inovação se torna indispensável. As abordagens do design, tanto mais intangíveis - como o design estratégico e de serviços, quanto as tangíveis - gráfico, de

Anais do $10^{\circ} \mathrm{CIDI}$ e $10^{\circ} \mathrm{CONGIC}$

Kelli C.A.S. Smythe, Rafael de Castro Andrade (orgs.)

Sociedade Brasileira de Design da Informação - SBDI

Curitiba | Brasil | 2021
Proceedings of the $10^{\text {th }} \mathrm{CIDI}$ and $10^{\text {th }}$ CONGIC

Kelli C.A.S. Smythe, Rafael de Castro Andrade (orgs.)

Sociedade Brasileira de Design da Informação - SBDI Curitiba | Brazil | 2021 
interfaces e da informação, mostram-se como caminhos para o setor desenvolver uma gestão mais inovadora. Assim, o presente estudo tem como objetivo investigar as diferentes percepções dos atores envolvidos sobre as contribuições do design nos processos de inovação da gestão pública.

\section{O design como solucionador de problemas complexos}

Para contextualização, considera-se importante mencionar a visão contemporânea do design na qual a pesquisa se baseia. $O$ design, dentre as suas múltiplas definições, pode ser considerado uma área transdisciplinar de visão sistêmica que, por meio de métodos projetuais criativos, visa criar processos dinâmicos e soluções que alteram a realidade atual.

O espectro de aplicação da área é amplo, porém, a abordagem centrada no usuário se mantém inerente. Para Stickdorn e Schneider (2014, p.13), "todos os processos de design têm em comum a abordagem centrada no usuário, o que faz todo produto ou serviço projetado ser desenvolvido a partir das necessidades e desejos do mesmo."

Consequentemente, por vivenciar-se uma realidade contemporânea cada vez mais complexa, é natural que os processos projetuais se voltem para as questões relacionadas aos desafios presentes, sem se descolar da realidade (Cardoso, 2016). Desafios que se relacionam com os wicked problems.

Nesse contexto, a organização da informação e a sua tradução em interfaces comunicativas que conversem de forma clara e eficiente com todos os envolvidos se mostra muito necessária.

\section{O design e a inovação no setor público}

As contribuições do design estão pautadas nos processos criativos e sistemáticos que envolvem as pessoas na exploração de problemas e oportunidades, no desenvolvimento e visualização de novas ideias e testagem de novas soluções.

Dessa forma, o designer assume o papel de mediador, com habilidades multidisciplinares, estruturando os processos colaborativos e traduzindo informações complexas em informações facilmente entendidas pelos envolvidos, favorecendo a participação ativa no processo e o desenvolvimento de soluções de forma sistemática.

Para Bason (2010; 2017), a abordagem do design contribui para a criação de soluções testadas e experimentadas; para a melhoria da organização e modelos de governança e para uma cultura de trabalho mais inovadora. Além de criar ambientes mais produtivos, colaborativos e cocriativos, gerando resultados que entregam mais valor para a sociedade.

Dessa maneira, é essencial entender por que o setor público deve buscar práticas mais inovadoras. No cenário complexo atual, torna-se necessário pensar em novos meios de abordar os problemas complexos, pois esses desafiam o setor público a prover políticas inovadoras. Em muitos casos, a inovação se tornou um imperativo, e não uma mera opção (Cavalcante et al., 2017). 
Acredita-se que a abordagem inovadora formaliza a busca por novas respostas e maneiras de fazer, otimizando os processos e as trocas de informações por meio de abordagens mais sistêmicas, participativas e visuais.

\section{Método}

A pesquisa consiste em uma abordagem qualitativa e exploratória de produção de conhecimento, levantando as percepções de atores públicos sobre o tema e produzindo uma discussão inicial diagnóstica sobre as diferentes ações realizadas no Governo Federal relacionadas à design e inovação.

Para tanto, o processo de elaboração do trabalho se deu em três eixos: o teórico, o empírico e o de síntese. O eixo teórico buscou compreender o panorama geral a partir da visão de autores especialistas no assunto. Já no eixo empírico, foram realizadas entrevistas semiestruturadas com pessoas que vivenciaram diferentes experiências no setor público (total $n=11)$, desde os que buscam explicitamente a inovação $(n=8)$ aos que não atuam em uma busca explícita $(n=3)$, entendendo suas diferentes perspectivas sobre as práticas cotidianas e os principais desafios e oportunidades percebidos. Elas foram selecionadas a partir da identificação de ações de inovação no Governo Federal. Como uma pesquisa qualitativa, nesta etapa foram realizadas entrevistas com cerca de $2 \mathrm{~h}$ com cada participante, compreendendo a percepção da vivência de cada entrevistado, com o fim de agregar informações ao levantamento teórico realizado, criando insights e identificando padrões ou discordâncias nas percepções. As entrevistas foram gravadas e analisadas posteriormente, verificando-se suas afinidades e pontos de discordância. Por fim, o conhecimento coletado a partir das abordagens teóricas e empíricas foi compilado, gerando discussões iniciais sobre as contribuições do design dentro da inovação pública brasileira.

\section{Percepções sobre a prática do design no setor público}

Notou-se na etapa empírica da pesquisa que, no contexto do setor público, o termo design é mais utilizado ao se referir às ferramentas e dinâmicas que são conhecidas por serem da área. No que tange a mudança sistêmica, fala-se inovação. Portanto, os dois conceitos caminham juntos e neste artigo, quando se fala de design, também se fala de inovação. Para Ellen Kiss (apud Rocha, 2017),

"design é o que integra criatividade e inovação. É a disciplina de transformar ideias em tangíveis práticos e atrativos para usuários e consumidores. Design pode ser definido como a criatividade aplicada com foco em uma determinada intenção." (apud Rocha, 2017)

Sabendo disso, algumas abordagens de design foram entendidas como relevantes ao longo da pesquisa, mostrando-se presentes na gestão pública. Assim, são apresentadas sínteses dessas percepções corroboradas pelas falas dos entrevistados. Elas foram compiladas em quatro principais tópicos de discussão, sumarizados a seguir. 


\section{Metodologias e ferramentas}

Inicialmente, as metodologias e ferramentas normalmente associadas à prática do design se mostram como a maneira mais simples de inserir processos inovadores nas dinâmicas das equipes, desafiando o modus operandi tradicional e propondo, assim, novas maneiras de discussão. Porém, a inovação é alcançada quando estas metodologias e ferramentas são internalizadas a ponto de serem realizadas naturalmente, quando o modo "inovador" se torna o modo de trabalho.

Certos "rituais" do trabalho colaborativo (uso de post its, disposição das reuniões em rodas, dinâmicas que dão voz a todos os envolvidos, dentre outros) podem parecer superficiais quando o porquê de estarem sendo realizados não é bem compreendido, como apontou uma entrevistada. Os precursores da inovação têm que enfrentar o desafio de fazer entender que não é o processo pelo processo, mas sim, que a sua realização propõe uma dinâmica mais livre e cria um espaço com mais liberdade para pensar em novas soluções de forma mais rápida e prática.

\section{Colaboração e participação}

No que tange à participação, uma das contribuições culturais que o design traz, pela sua natureza transdisciplinar, é a formação de equipes diversas. Entendendo o papel estratégico de cada pessoa no processo, torna-se possível criar equipes que atuam de ponta a ponta, segundo um dos entrevistados.

Para um entrevistado, a cocriação e participação nos serviços públicos "é a riqueza de todo o processo de design thinking" e, quando realizadas, geram resultados além do esperado. Porém, estes processos vão na contramão da estrutura do setor, que é extremamente hierarquizada e setorizada. Por isso, espaços - como os laboratórios de inovação - que permitam essa flexibilidade são fundamentais para a inserção de processos mais colaborativos dentro da gestão pública.

A diversidade de atores enriquece o processo e, se realizada por meio de interfaces e artefatos de comunicação que contribuam para a dinâmica, possibilita que as pessoas se expressem ativamente, pois o uso de ferramentas concretas (como protótipos) em vez de abstratas (modelos conceituais, formalismos) ativa o conhecimento tácito da atividade, facilitando a visualização de futuros alternativos, inclusive, da própria organização social da atividade (Crabtree, 2003).

\section{Comunicação e visualização de informações}

Ao utilizar práticas de design nos ambientes de trabalho, é natural que estas venham acompanhadas de sistemas de informação e comunicação otimizados, por meio do uso do design gráfico e da informação, abordagens transversais à prática do design.

Segundo um dos entrevistados, os processos colaborativos - que frequentemente utilizam interfaces e protótipos para auxiliar nas interações - introduzidos a partir de práticas do design thinking, fizeram com que a sua equipe passasse a pensar mais na informação que precisa 
comunicar, tanto internamente quanto para o público. Por isso, a busca por maneiras de criar informações mais claras e úteis pela utilização de novos softwares não tão usados no setor se tornou rotina.

Assim como, segundo o mesmo entrevistado, a tradução das informações em artefatos visuais, como infográficos, esquemas e ilustrações, se tornou prioridade no seu contexto, pois, com a inserção dessa prática, notou-se que o público externo teve contato com uma informação mais clara e compreensível.

\section{Experimentação e erro}

Para um dos participantes, a possibilidade de inovar está intimamente ligada à abertura para errar e testar coisas. A cultura de aversão ao erro presente no setor público dificulta a realização de processos alternativos. Segundo outro entrevistado, "as pessoas veem o erro como inimigo e não entendem que ele faz parte do processo". A prática do design thinking contribuiu para o entendimento de que, mesmo que não haja o cenário ideal, os testes podem ser feitos de maneiras simples, em etapas intermediárias.

As iniciativas que introduzem as práticas inovadoras no governo, como os laboratórios de inovação, corroboram para este contexto oferecendo um ambiente livre e seguro para geração de ideias e testes. Apresentando, assim, a prática experimental em momentos pontuais, possibilitando que os servidores a introduzam em seus cotidianos.

Por fim, entende-se que as abordagens práticas apresentadas são as de maior destaque dentro da discussão entre design e inovação no setor público. Por meio delas, é possível apresentar novas maneiras de criar e solucionar problemas, contribuindo para uma gestão pública mais criativa e inovadora.

\section{Considerações finais}

A pesquisa propôs uma discussão inicial sobre as principais contribuições da abordagem do design dentro do contexto de inovação da gestão pública no Brasil, compreendendo percepções de agentes públicos que atuam neste contexto. Além disso, é construído um panorama inicial para que outras pesquisas possam ser realizadas, aprofundando problemáticas e características específicas, contribuindo para o avanço do conhecimento sobre o design e a inovação pública.

\section{Referências}

Bason, C. (2017). Leading public design discovering human-centred governance. Bristol: Policy Press.

Bason, C. (2010). Leading public Sector Innovation Co-creating for a Better Society. Bristol: Policy Press.

Cardoso, R. (2016). Design para um mundo complexo. São Paulo: Ubu Editora. 
Cavalcante, P., Camões, M., Cunha, B., \& Severo, W. (2017) Inovação no setor público: teoria, tendências e casos no Brasil. Brasília: Enap.

Crabtree, A., (2003). Designing Collaborative Systems: A Practical Guide to Ethnography. London: Springer.

Sanders, E. (2002). From User-Centered to Participatory Design Approaches. Em: In Design and the Social Sciences. Taylor \& Francis Books Limited.

Stickdorn, M., \& Schneider, J. (2014). Isto é Design Thinking de Serviços: Fundamentos, Ferramentas, Casos. Porto Alegre: BOOKMAN EDITORA LTDA.

Rocha, I. (2017). Afinal, o que design tem a ver com inovação? Disponível em: <https://designculture.com.br/afinal-o-que-o-design-tem-a-ver-com-inovacao>. Acesso em 5 de abr 2021.

\section{Sobre os autores}

Dara Costa Rattes, UnB, Brasil <daracrattes@gmail.com>

Tiago Barros Pontes e Silva, Dr., UnB, Brasil<tiagobarros@unb.br> 